\title{
An electronic colonoscopy record system enables detailed quality assessment and benchmarking of an endoscopic service
}

\author{
A Benamro, MB BCh; J L Bruce, FCS (SA); D L Clarke, PhD \\ Gastroenterology Unit, Grey's Hospital, Pietermaritzburg, and Department of Surgery, School of Clinical Medicine, \\ College of Health Sciences, Nelson R Mandela School of Medicine, University of KwaZulu-Natal, Durban, South Africa
}

Corresponding author: D L Clarke (damianclar@gmail.com)

\begin{abstract}
Background. Competence in colonoscopy, which is a technically difficult procedure, requires adequate exposure to it and the maintenance of a detailed logbook. Without an electronic record this is difficult to achieve. By implementing an electronic medical record system we aimed to perform a detailed quality assessment audit of colonoscopy, to benchmark our results and generate accurate logbooks for individual endoscopists.

Methods. We reviewed the prospectively maintained Hybrid Electronic Medical Registry (HEMR). Colonoscopies performed between March 2013 and March 2014 were reviewed, and for competency, quality metrics were derived from the guidelines of the American Society of Gastroenterology.

Results. A total of 843 colonoscopies were performed. Seven hundred and seventy procedures were performed by three staff endoscopists who each performed over the required 150 procedures annually $(n=197,338$ and 235$)$. The remaining $73(8.7 \%)$ were performed by other staff. In 105 cases (12.5\%), bowel preparation was deemed to be inadequate, which caused the procedure to be abandoned in 34 cases. A total of 64 cases were deemed to be incomplete because of obstructing lesions $(n=26)$, extensive diverticulosis $(n=4)$, technical difficulty $(n=31)$ and patient discomfort $(n=3)$. There were two complications recorded: perforation $(n=1)$ and bleeding $(n=1)$.

Conclusions. The HEMR system enabled the audit of experiences with colonoscopy in our institution. Our results are broadly compatible with the international literature and with a number of guidelines. The development of an electronic record system is a major advance, as it enables meaningful benchmarking and the generation of accurate procedural logbooks.
\end{abstract}

S Afr Med J 2015;105(12):1061-1063. DOI:10.7196/SAMJ.2015.v105i12.10115

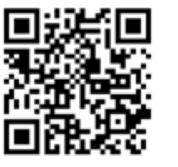

Flexible fibreoptic colonoscopy is the current gold standard investigation for diseases of the colon, as it allows direct visualisation of the entire colon and several therapeutic interventions. ${ }^{[1-3]}$ However, colonoscopy is technically difficult to master and is associated with a significant number of complications. There has therefore been considerable interest in attempts to standardise the teaching of the procedure and in the accreditation of endoscopists, and several regulatory bodies and societies have developed norms and quality markers for endoscopists. ${ }^{[1-3]}$ The advent of dedicated colonoscopic screening programmes around the world has focused attention on the sensitivity and specificity of colonoscopy, and the endoscopist must provide proof of competency based on detailed logbooks. Logbooks are also required for training purposes. Most examining bodies rely on them to ensure that candidates sitting board and fellowship examinations have been exposed to an adequate spectrum of pathology and procedures and have documented evidence that they are competent in these procedures. ${ }^{[4,5]}$ Previously, all record-keeping in our institution was paper based, which made it difficult to record and analyse data, and it was impossible to monitor quality markers and to benchmark the service. The development of our electronic medical record systems enabled us to keep detailed electronic records of all endoscopic procedures. ${ }^{[6,7]}$ By keeping these data in a relational database, we can perform detailed audits of colonoscopies at our institution. We aimed to use data from such an audit to benchmark our results against international quality guidelines and to provide individual endoscopists with a procedural logbook.

\section{Setting}

Grey's Hospital is a tertiary hospital in Pietermaritzburg, KwaZuluNatal Province (KZN), South Africa. The city has a population of just under one million people. Grey's Hospital is the tertiary referral hospital for the entire western part of KZN, which is a very rural area with a population of about two million people. The Gastroenterology Unit at Grey's functions with two colonoscopes, and is staffed by a core team of dedicated nursing staff. A dedicated colorectal surgical service at Grey's is staffed by a senior surgeon, a single subspecialist surgeon ( $<5$ years' clinical experience) and a single colorectal fellow in training. However, not all colonoscopies are performed by these three doctors. Since 2013 Grey's Hospital has run a Hybrid Electronic Medical Registry (HEMR) that captures the admission, operative, endoscopic and discharge data of all surgical patients in a relational database. ${ }^{[7]}$ This database is clinician maintained and audited.

\section{Methods}

We retrospectively reviewed the prospectively maintained HEMR for all colonoscopies performed between March 2013 and March 2014. These data were used to generate a procedural logbook for each endoscopist and, for competency, were based on the published guidelines $^{[3]}$ of the American Society of Gastroenterology (ASGE), specifically noting the following quality markers: $(i)$ number of procedures per individual endoscopist; (ii) quality of the bowel preparation; (iii) number of times the caecum was intubated; (iv) number of adenomas detected at each procedure; $(v)$ complications; and $(v i)$ number of incomplete procedures. 


\section{Results}

A total of 843 colonoscopies were performed. Fig. 1 documents the indications for the procedure.

Three colorectal service endoscopists, who each performed more than the required 150 procedures annually, performed a total of 770 procedures. The remaining 73 (8.7\%) were performed by other staff. In 105 cases (12.5\%), bowel preparation was deemed to be inadequate, which caused the procedure to be abandoned in 34 cases. A total of 64 cases were deemed to be incomplete because of obstructing lesions $(n=26)$, extensive diverticulosis $(n=4)$, technical difficulty $(n=31)$ and patient discomfort $(n=3)$. The completion rates of the three members of the colorectal team are documented in Table 1. Both endoscopists with more than a year's experience had completion rates approximating 98\%. Table 1 also documents the adenoma detection rate per endoscopist. There were two complications recorded: perforation $(n=1)$ and rectal bleeding $(n=1)$. Table 2 lists the complications against level of experience. Fig. 2 summarises the entire cohort.

\section{Discussion}

Increased awareness of quality issues in healthcare has resulted in the development of quality metrics to provide an index against which clinicians and institutions can measure their performance. Many international associations for flexible endoscopy have therefore promulgated quality metrics for various endoscopic procedures. We used the guidelines of the ASGE, and benchmarked our unit's experience against these guidelines. Incomplete examinations owing to obstructing lesions or faecal obstruction are regarded as failed procedures, and there should be a polyp detection rate of $\geq 20 \%$. The data in the HEMR enabled comparison of our experience with those of published guidelines:

1. Number of procedures. An endoscopist must be affiliated with a screening centre and must have performed at least 1000 examinations over his/ her professional lifetime. There should have been at least 150 examinations performed in the preceding 12 months by each endoscopist. ${ }^{[1-5]}$ Three of the staff performing the procedure worked in the colorectal service and easily met this requirement, suggesting that we have an adequate caseload for the training of colorectal specialists. The remaining procedures were preformed by a variety of endoscopists from different services.

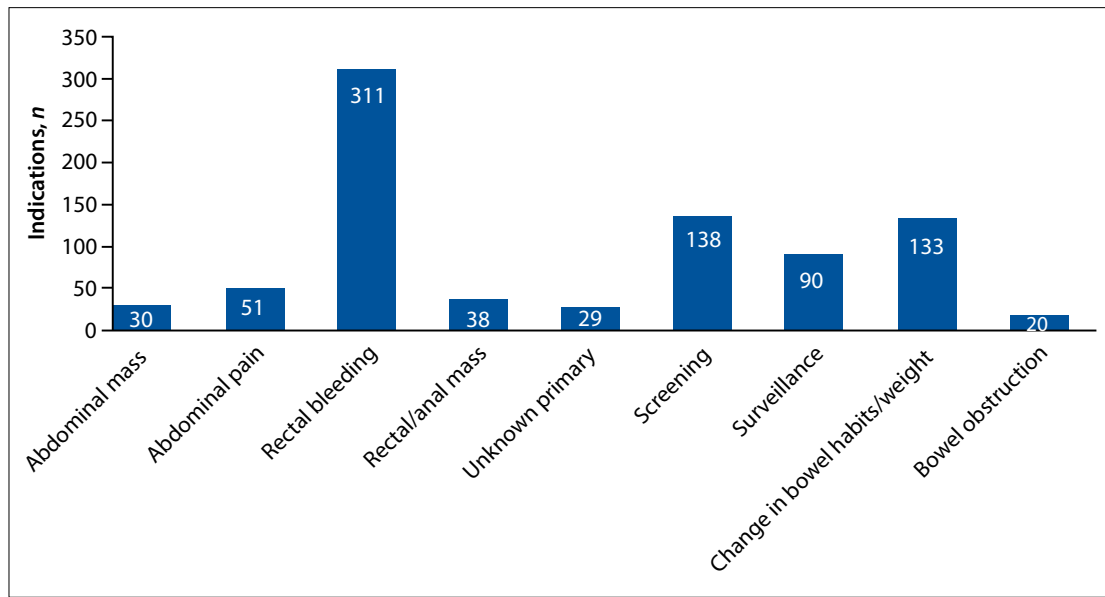

Fig. 1. Indications for lower colonoscopy.

Table 1. Polyps detected and completed scopes for individual endoscopists

\begin{tabular}{llll}
\hline & $\begin{array}{l}\text { Polyps detected } \\
\boldsymbol{n}(\%)\end{array}$ & $\begin{array}{l}\text { Completed scopes } \\
\boldsymbol{n}(\%)\end{array}$ & $\begin{array}{l}\text { Total cases } \\
\boldsymbol{N}\end{array}$ \\
\hline $\begin{array}{l}\text { Senior colorectal specialist, }>5 \text { years' } \\
\text { experience }\end{array}$ & $23(11.5)$ & $198(99.0)$ & 200 \\
$\begin{array}{l}\text { Colorectal specialist, }<5 \text { years' } \\
\text { experience (second year) }\end{array}$ & $18(7.7)$ & $227(96.6)$ & 235 \\
$\begin{array}{l}\text { Colorectal trainee (first year) } \\
\text { (28 }\end{array}$ & & $228(6.3)$ & 338
\end{tabular}

Table 2. Complications by level of medical expertise, all patients

\begin{tabular}{llll}
\hline & Type of complication & $\begin{array}{l}\text { Complications } \\
\boldsymbol{n}(\%)\end{array}$ & $\begin{array}{l}\text { Total procedures } \\
\boldsymbol{N}\end{array}$ \\
\hline Non-colorectal trainee & Rectal bleeding & $1(10.0)$ & 10 \\
Non-colorectal consultant & Perforation & $1(10.0)$ & 10
\end{tabular}

2. Quality of bowel preparation. The ASGE suggests that the percentage of outpatient examinations with inadequate bowel preparation should not exceed $15 \%$ of all procedures. The reported incidence of $13 \%$ in this series was within these guidelines. Inadequate bowel preparation makes the procedure technically more challenging and increases the risk of an incomplete study and of complications. ${ }^{[1-3,8,9]}$

3. Rate of complete colonoscopy. For a study to be deemed complete, the endoscopist must intubate the terminal ileum and visualise the appendiceal orifice. The rate of complete colonoscopy should be $>90 \%$ for diagnostic colonoscopy and $>95 \%$ for screening colonoscopy; these rates are being achieved in our endoscopy service. ${ }^{[1-3]}$ Both endoscopists with more than a year's experience with the procedure had significantly higher completion rates than the first-year trainee.

4. Detection rate of adenoma. Each endoscopist should identify one or more adeno- matous polyps in at least $25 \%$ of men and $15 \%$ of women aged $>50$ years who are undergoing a screening colonoscopy. Although few of our procedures were true screening colonoscopies, our detection rate is in keeping with this. ${ }^{[1-3,10,11]}$

5. Complications. The rate of perforation secondary to colonoscopy is currently in the order of one perforation per 1000 1400 examinations. ${ }^{[1]}$ Table 2 summarises the complications. Our complication rate is slightly higher than the suggested rate, based on the ASGE guidelines. Ongoing audit is necessary to determine whether this problem is persistent and whether a quality improvement programme is necessary to address this..$^{[1-3,10,12]}$

The ongoing drive to ensure that training is quantified and standardised across national centres has involved the mandatory keeping of procedural logbooks. However, these logbooks have mostly been manual, and concerns have been raised that they 


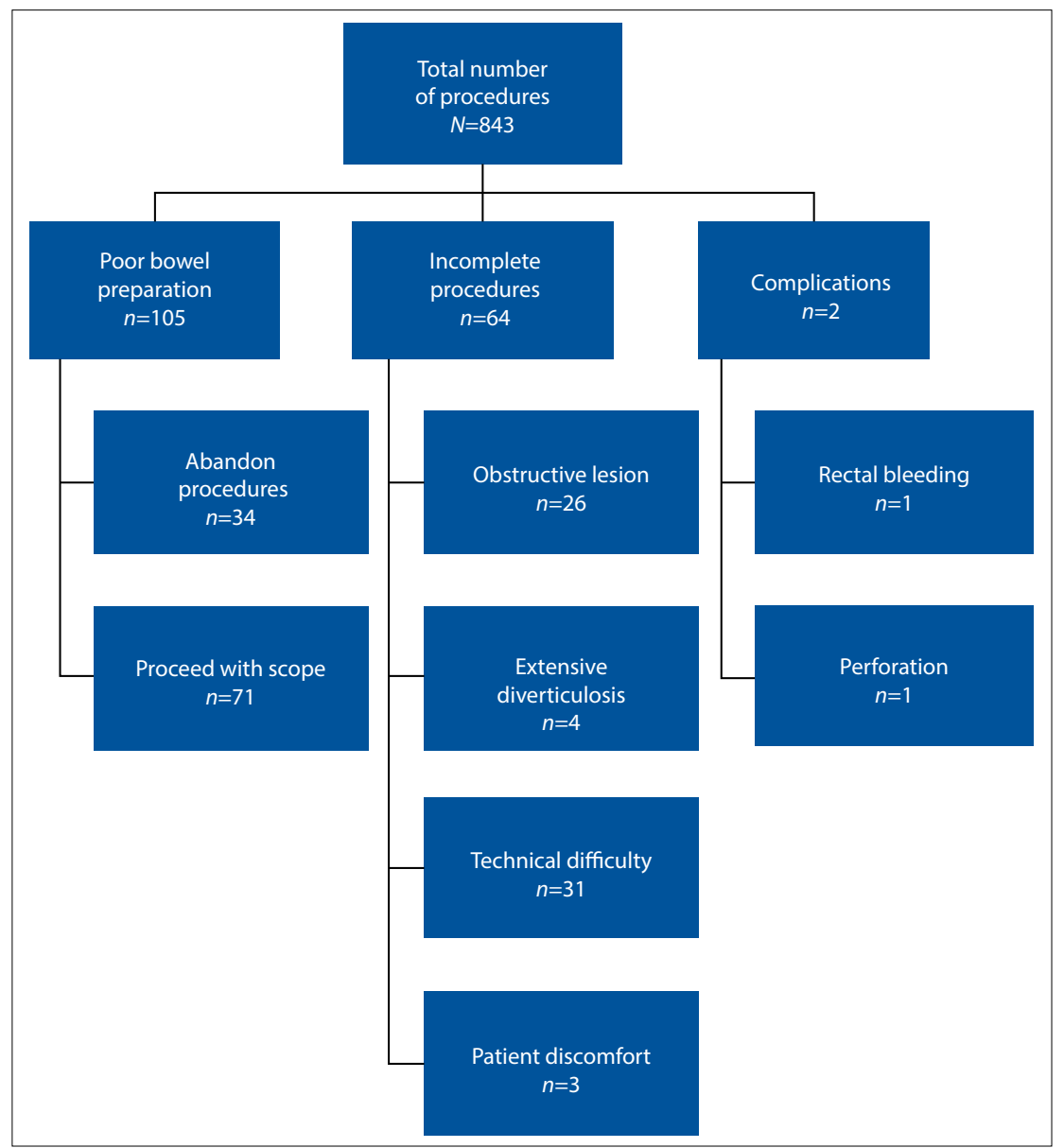

Fig. 2. Schematic breakdown of the entire cohort.

are not standardised. A recent review of operative logbooks found that the method of logging data is trainee-dependent and not uniform, making their evaluation extremely tedious. ${ }^{[4,5]}$ The development of the HEMR allows individuals to keep an accurate electronic record of procedures performed thereby improving the quality and usability of procedural logbooks. The drive to develop subspecialist training programmes appropriate for both subspecialist trainees. The three staff members from the colorectal service each met this requirement, suggesting that our caseload is adequate for the training of colorectal specialists. The development of this HEMR system enabled our service to quantify our workload accurately and to benchmark our service against international guidelines. We could also establish a workload that can be used to support training initiatives. This has implications for service delivery and educational purposes.

\section{References}

1. Chen SC, Rex DK. The endoscopist can be more powerful than age and male gender in predicting adenoma detection at colonoscopy. Am J Gastroenterol 2007;102(4):856-861. [http:// colonoscopy. Am f Gastroenterol 2007;102(4):

2. Rex DK, Petrini JL Baron TH, et al Quality indicators of the Rex DK, Petrini JL, Baron TH, et al. Quality indicators of the
colonoscopy. Am J Gastroenterol 2006;101(4):873-885. [http:// colonoscopy. Am J Gastroenterol 2006.10

dx.doi.org/10.1016/j.gie.2014.07.058]
American Society for Gastrointestinal Endoscopy and American College of Gastroenterology. http://www.asge.org/ uploadedFiles/Publications_(public)/Practice_guidelines/2014_ Quality_in_endoscopy_set.pdf (accessed 10 October 2015).

4. Colleges of Medicine of South Africa. Fellowship of the College of Surgeons of South Africa: FCS (SA), 2013. http://www. collegemedsa.ac.za/view_exam.aspx?examid=46 (accessed 3 December 2013).

5. Kruger D, Veller MG. Exposure to key surgical procedures during specialist general surgical training in South Africa. S Afr J Surg 2014;52(4):96-100. [http://dx.doi.org/10.7196/sajs.2162]

6. Clarke DL. Trauma quality improvement: The Pietermaritzburg Metropolitan Trauma Service experience with the development of a comprehensive structure to facilitate quality improvement in rural trauma and acute care in KwaZulu-Natal, South Africa. in rural trauma and acute care in KwaZulu-Natal, South Africa.
S Afr Med J 2015;105(2):92-95. [http://dx.doi.org/10.7196/ S Afr Med J 2015;105(2):92-95. [http://dx.doi.org/10.7196/ SAMJ.8792

7. Laing GL, Bruce JL, Skinner DL, Allorto NL, Clarke DL, Aldous C. Development, implementation and evaluation of a hybrid electronic medical record system specifically designed for a developing world surgical service. World J Surg 2014;38(6): 13881397. [http://dx.doi.org/10.1007/s00268-013-2438-2]

8. Ben-Horin S, Bar-Meir S, Avidan B. The impact of colon cleanliness assessment on endoscopist's recommendation for follow-up colonoscopy. Am J Gastroenterol 2007;102(12):26802685. [http://dx.doi.org/10.1111/j.1572-0241.2007.01486x]

9. Thomas-Gibson S, Rogers P, Cooper S, et al. Judgement Thomas-Gibson S, Rogers $\mathrm{P}$, Cooper S, et al. Judgement of the quality of bowel preparation at screening flexible
sigmoidoscopy is associated with variability in adenoma sigmoidoscopy is associated with variability in adenoma
detection rate. Endoscopy 2006;38(5):456-460. [http://dx.doi. detection rate. Endoscopy
org $110.1055 / \mathrm{s}-2006-925259]$

10. Panteris V, Haringsma J, Kuipers EJ. Colonoscopy perforation Panteris V, Haringsma J, Kuipers EJ. Colonoscopy perforation
rate, mechanism and outcome: From diagnostic to therapeutic colonoscopy. Endoscopy 2009;41(11):941-951. [http://dx.doi. org/10.1055/s-0029-1215179]

11. Pickhardt PJ, Nugent PA, Mysliwiec PA, Choi JR, Schindler WR. Location of adenomas missed by optical colonoscopy. Ann Intern Med 2004;141(5):352-359. [http://dx.doi.org/10.7326/00034819-141-5-200409070-00009]

12. Crispin A, Birkner B, Munte A, Nusko G, Mansmann U. Process quality and incidence of acute complications in a series of more than 230,000 outpatient colonoscopies. Endoscopy 2009:41(12):10181025. [http://dx.doi.org/10.1055/s-0029-1215214] 